\title{
RECENT PROGRESS IN MESOSPHERIC GRAVITY WAVE STUDIES USING NIGHTGLOW IMAGING SYSTEMS
}

\author{
Michael J. Taylor ${ }^{1}$, William R. Pendleton $\mathrm{Jr}^{2}$, Pierre-Dominique Pautet ${ }^{3}$, Yucheng Zhao ${ }^{4}$, Chris $01 \operatorname{sen}^{5}$, \\ Hema Karnam Surendra Babu ${ }^{6}$, Amauri F. Medeiros ${ }^{7}$ and Hisao Takahashi ${ }^{8}$
}

Recebido em 17 fevereiro, 2006 / Aceito em 28 fevereiro, 2007

Received on February 17, 2006 / Accepted on February 28, 2007

\begin{abstract}
A variety of optical remote sensing techniques have now revealed a rich spectrum of wave activity in the upper atmosphere. Many of these perturbations, with periodicities ranging from $\sim 5 \mathrm{~min}$ to many hours and horizontal scales of a few tens of $\mathrm{km}$ to several thousands $\mathrm{km}$, are due to freely propagating atmospheric gravity waves and forced tidal oscillations. Passive optical observations of the spatial and temporal characteristics of these waves in the mesosphere and lower thermosphere (MLT) region ( $\sim 80-100 \mathrm{~km})$ are facilitated by several naturally occurring, vertically distinct nightglow layers. This paper describes the use of state-of-the-art groundbased CCD imaging techniques to detect these waves in intensity and temperature. All-sky $\left(180^{\circ}\right)$ image measurements are used to illustrate the characteristics of small-scale, short period ( $<1$ hour) waves and to investigate their seasonal propagation and momentum impact on the MLT region. These results are then contrasted with measurements of mesospheric temperature made using a new temperature mapping imaging system capable of determining induced temperature amplitudes of a large range of wave motions and investigating night-to-night and seasonal variability in mesospheric temperature.
\end{abstract}

Keywords: gravity waves, mesospheric dynamics, airglow imaging, seasonal variability.

RESUMO. 0 espectro de ondas na alta atmosfera tem sido revelado por uma variedade de técnicas de sensoriamento remoto ótico. Muitas destas perturbações apresentam períodos variando de 5 minutos a algumas horas e escalas horizontais que variam de dezenas a milhares de quilômetros e são devidas a livre propagação de ondas de gravidade e marés atmosféricas. Observações óticas das características espacial e temporal destas ondas na região ( 80-100 km) da mesosfera e baixa termosfera (MLT) utilizam a variação da aeroluminescência atmostérica. Este trabalho descreve o estado da artedas técnicas que utilizam o imageamento via CCD para detectar estas ondas através das variações provocadas na intensidade e temperatura. Medidas de um imageador de céu todo ( $A / /$-sky, $180^{\circ}$ ) são usadas parar determinar as características de ondas de pequena escala e curto período ( $<1$ hora) e investigar a sazonalidade da direção propagação destas ondas, como também o depósito de momento na região da MLT. Estes resultados são comparados com medidas da temperatura atmosférica realizadas usando um novo sistema de imageamento de mapeamento da temperatura mesosférica capaz de determinar variações nas amplitudes da temperatura provocadas pelas ondas de gravidade através da investigação da variabilidade noturna da temperatura mesostérica.

Palavras-chave: ondas de gravidade, dinâmica da mesosfera, luminescência atmosférica, sazonalidade, imageador, oscilações atmosféricas.

Center for Atmospheric and Space Sciences, Utah State University, Logan, Utah 84322, USA. Phone: +01 (435) 797-3919; Fax: +01 (435) 797-2992 -E-mails: ${ }^{1}$ mtaylor@cc.usu.edu; ${ }^{2}$ wpen@cc.usu.edu; ${ }^{3}$ dominiquepautet@gmail.com; ${ }^{4}$ yucheng@cc.usu.edu; ${ }^{5}$ cmellob@gmail.com; ${ }^{6}$ hema_sb@rediffmail.com 7 Universidade Federal de Campina Grande, Centro de Ciências e Tecnologia, Unidade Acadêmica de Física, Av. Aprígio Veloso, 882, Bodocongó - $58109-970$ Campina Grande, PB, Brazil. Phone: +55 (83) 310-1196; Fax: +55 (83) 310-1196 - E-mail: afragoso@df.ufcg.edu.br

${ }^{8}$ INPE, P.O. Box 515, 12245-970 São José dos Campos, SP, Brazil. Phone: +55 (12) 3945-7145; Fax: +55 (12) 3945-6740 - E-mail: hisaotak@laser.inpe.br 


\section{INTRODUCTION}

It is now known that the largest systematic influence on the mesosphere and lower thermosphere (MLT) region (altitude range 80-100 km) results from relatively small-scale freely propagating gravity waves. This is because of their ability to transport significant amounts of energy and momentum up from the lower atmosphere source regions to the MLT region where they strongly influence the mean wind and the larger-scale tidal wave motions. As these short-period waves steepen due to adiabatic wave growth with altitude (or by reaching critical layers), they deposit their energy and momentum mainly in the MLT region. In so doing they give rise to horizontal motions, which act to oppose the background flow and produce closure of the mesospheric jet (e.g. Holton, 1983; Garcia \& Solomon, 1985), as well as vertical motions resulting in strong adiabatic cooling responsible for the unexpectedly cold summer mesopause at polar latitudes (as much as $90 \mathrm{~K}$ below the radiative equilibrium level). Thus, gravity waves, in particular small-scale, short period waves (e.g. Fritts \& Vincent, 1987) are now understood to be a key element in defining both the large-scale circulation, and the regional thermal structure and dynamical variability of the atmosphere at altitudes extending from the stratosphere into the MLT region.

Knowledge of the spatial and temporal characteristics, geographic distribution and seasonal variability of these waves at MLT heights is therefore of key interest. However, as the mean winds and tides in the intervening atmosphere can modulate the gravity wave fluxes, and as they both vary strongly with latitude and season, the upward flux of momentum at a given site and time is expected to vary significantly. Optical remote sensing measurements have established the global presence of these waves at equatorial mid- and high-latitudes and their basic properties. However, their momentum coupling and effects on the MLT region have only been investigated from a limited number of sites, and their seasonal variability are not well known for any place on earth.

Of equal importance to this investigation is accurate knowledge of the basic properties of the MLT region (background temperature and wind fields) in which these waves propagate and dissipate. Measurements using meteor radar and more recently powerful Na lidar systems have provided unprecedented information on the vertical structuring of the MLT and the influence of tides. In particular, Na wind-temperature lidar systems provide high-resolution, height-resolved measurements of the wind and temperature field over the range $\sim 80-100 \mathrm{~km}$ (e.g. States \& Gardner, 2000) essential for investigating the effects of tides and gravity waves on the MLT region. However, due to their complexity lidar systems are usually operated only 2-3 nights/month and climatology studies, therefore, lack necessary details associated with spring and fall transitions and shorter term variability due to planetary waves, tides and gravity waves.

Long-term optical measurements can provide important information, not only on the properties of the gravity waves but also in the background wind and temperature field. Here we present some recent results on gravity wave seasonal anisotropy obtained using all-sky (ASI) monochromatic imagers and novel measurements of seasonal temperature variability in the MLT at low-latitudes using the CEDAR Mesospheric Temperature Mapper (MTM). As we will show, imagers are becoming powerful tools for remote-sensing studies of the upper atmospheric dynamics as they provide key data complementary to those usually obtained using established radar and other passive and active optical techniques. In particular, imagers are relatively low cost and can be run automatically for extended periods (years) essential for long-term investigations of the MLT climatology.

\section{IMAGE MEASUREMENTS OF SHORT-PERIOD GRAVITY WAVES}

Images of the naturally occurring nightglow emissions afford an excellent method for investigating the horizontal morphology and dynamics of short-period (typically $<1$ hour) gravity waves. There are several prominent emissions at MLT heights which can be used for this study: the near infra-red (NIR) $\mathrm{OH}$ bands (peak altitude $\sim 87 \mathrm{~km}$ ), the $\mathrm{O}_{2}(0,1)$ Atmospheric band $(\sim 94 \mathrm{~km})$, the $0 \mathrm{Ol}(557.7 \mathrm{~nm})$ green line $(\sim 96 \mathrm{~km})$ and the $\mathrm{Na} D$ $(589.2 \mathrm{~nm})$ doublet $(\sim 90 \mathrm{~km})$, all of which exhibit typical nighttime half-widths (FWHM) of 8-10 km. As gravity waves propagate through these layers they induce significant modulation in the line-of-sight brightness and rotational temperature which is detected as radiance "structure". Several instruments have been developed to investigate the morphology and dynamics of the nightglow emissions. However, the exceptional capabilities of high quantum efficiency CCD arrays for low-light imaging studies at visible and NIR wavelengths makes them the detectors of choice for many gravity wave studies. In particular, all-sky $\left(180^{\circ}\right)$ imagers provide unique two-dimensional information on the spatial and the temporal properties of short-period gravity waves ( 5-60 min) over a maximum (single site) area of $\sim 500,000 \mathrm{~km}^{2}$ (e.g. Taylor et al., 1995; Medeiros et al., 2003; 2004).

Figure 1 is a photograph of a Utah State University (USU) allsky imager (originally developed in 1993), mounted in a frame 


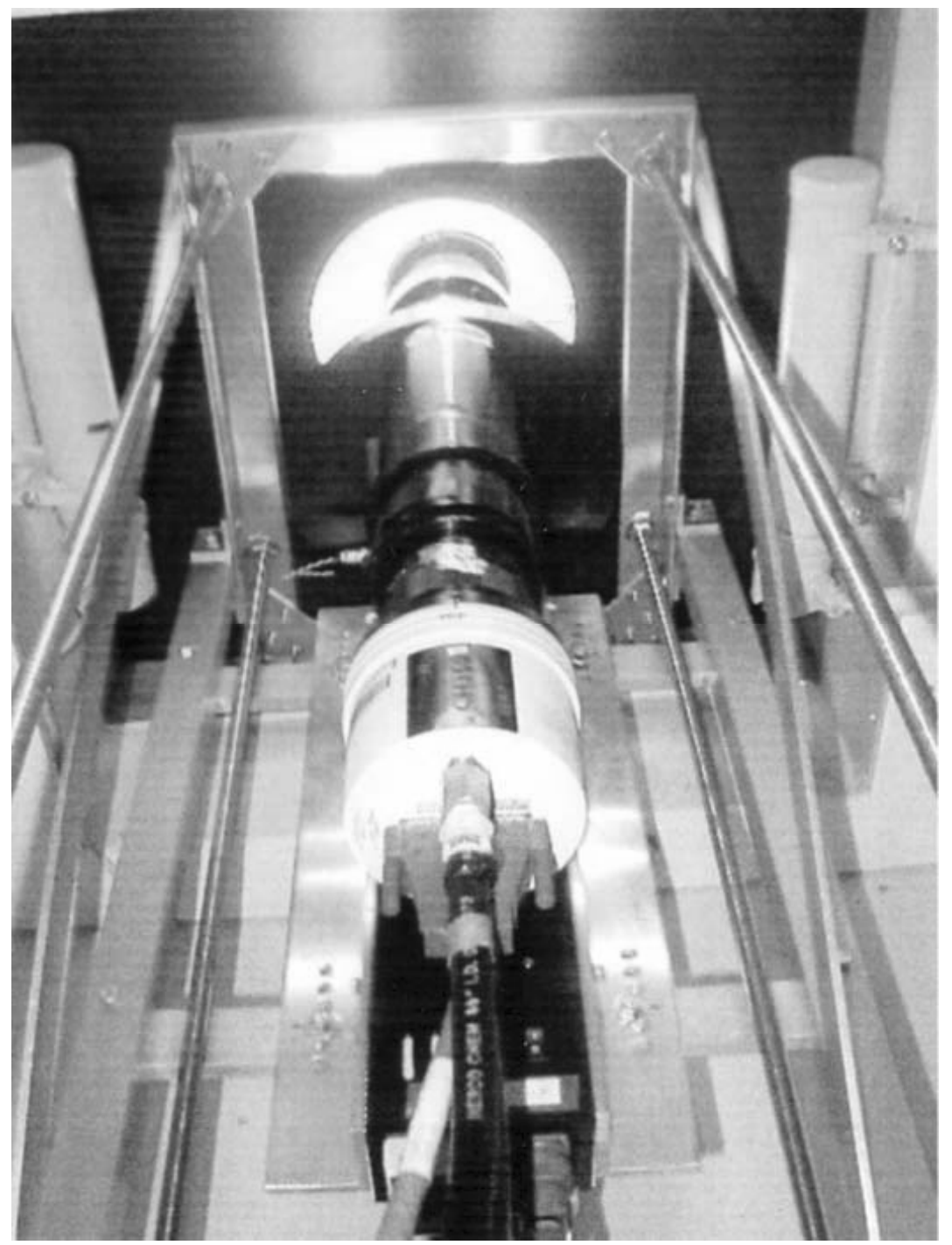

Figure 1 -All-sky, monochromatic CCD imager developed at Utah State University for imaging short-period gravity waves in the faint MLT emissions. The camera system is mounted vertically to view the night sky through a perspex dome.

under a perspex dome. A high-resolution $1024 \times 1024$ pixel, back-thinned CCD array is used providing excellent, low-noise measurements of the airglow emissions. The CCD is cooled to $-40^{\circ} \mathrm{C}$ to limit the dark current to typically a few electrons/ pixel/sec and a telecentric lens arrangement coupled to a 6position filter wheel is used to provide wide-field $\left(180^{\circ}\right)$ sequential images of selected airglow emissions (filter bandwidths $<2 \mathrm{~nm}$ ). Typical exposure time range from $15 \mathrm{sec}$ for the bright NIR OH bands to $90 \mathrm{sec}$ for the $\mathrm{Ol}(557.7 \mathrm{~nm})$ line emissions. This instrument is a compact, well-proven field system capable of autonomous operation, long-term operation with remote control and data access via the internet.
Figure 2 illustrates a short-period quasi-monochromatic wave event imaged near simultaneously in four different MLT airglow emissions $\left(\mathrm{Ol}, \mathrm{O}_{2}\right.$, $\mathrm{Na}$ and $\left.\mathrm{OH}\right)$. The data were obtained from Bear Lake Observatory (BLO), Utah, USA on 5 June 2002 and are typical of many of the spatially extensive, but short-period wave events detected from a number of sites at equatorial, mid- and high latitudes. In this example the stars have been removed, prior to spectral analysis to determine the horizontal wavelength $\left(\lambda_{h}=\right.$ $45 \mathrm{~km})$ and motion $\left(v_{h}=45 \mathrm{~m} / \mathrm{s}\right)$ of the waves pattern (observed period $15 \mathrm{~min})$. Note, the Milky Way is still evident as a bright band in the upper left of each image. Also note the presence of a set of much smaller-scale ripple waves in the lower-altitude 
( $\sim 87 \mathrm{~km}) \mathrm{OH}$ emission. These are mainly due to spatially localized shear or convective instabilities and unlike the gravity waves are generated in-situ (e.g. Taylor \& Hapgood, 1990; Hecht, 2004 and references therein).
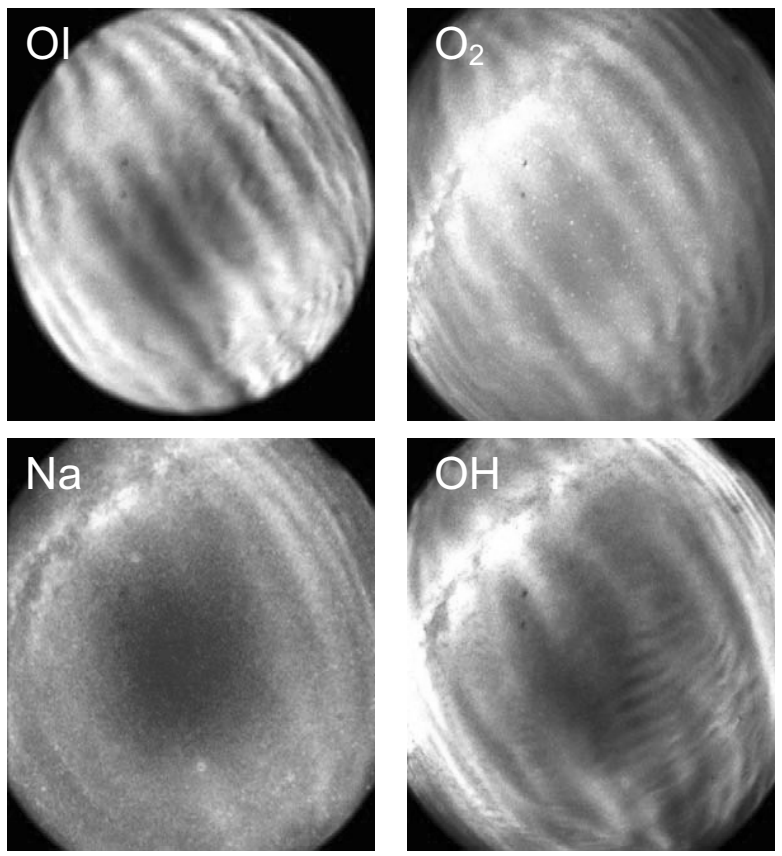

Figure 2 - Example of a spatially extensive short-period gravity wave event imaged near simultaneously in four nightglow emissions using an all-sky $\left(180^{\circ}\right)$ bare CCD imager. The data were obtained from BLO on 5 June, 2002. (Note: stars have been removed from these data to aid spectral analysis.)

Imaging systems are most sensitive to relatively fast-moving waves exhibiting vertical wavelengths somewhat greater than the layer thickness (i.e. $>8 \mathrm{~km}$ ) and horizontal wavelengths $\left(\lambda_{h}\right)$ $\sim 5-200 \mathrm{~km}$ (i.e. significantly less than the maximum field of view). This is exactly the range of scale sizes that are the most important drivers of the MLT region dynamics. The majority of these waves ( $\left(\lambda_{h}\right.$ up to a few hundred $\left.\mathrm{km}\right)$ are considered to be generated in the lower atmosphere by weather related disturbances such as convective activity, wind shear instabilities (jet streams), storms or fronts, or by orographic forcing (wind flow over mountainous regions). Image measurements of the airglow emissions can be made at any latitude and season providing a global, all year round capability. Such studies have revealed a wealth of small-scale wave activity from many sites around the world and it is not uncommon to observe several different wave patterns during the course of a night suggesting copious sources.

\section{GRAVITY WAVE ANISOTROPY}

An important result arising from airglow image analysis is that short-period waves often exhibit marked preference in their pro- pagation headings when observed over intervals of a few weeks. Such measurements made over the course of a year are still quite rare but they all indicate strong anisotropy that also appears to vary systematically with the seasons. Taylor et al. (1993) were the first to investigate this anisotropy in image data and attributed it to wave blocking by winds. Their results, obtained over a 3month period from Ft. Collins, Colorado, indicated that criticallayer filtering of the waves by the background winds in the intervening atmosphere (stratosphere and lower mesosphere) was an important factor in governing the propagation of wave energy (and momentum) into the MLT region. Critical layers occur when the horizontal wind vector along the direction of motion of the wave equals its observed horizontal phase speed (e.g. Tuan \& Tadic, 1982). Under these conditions the intrinsic frequency of the gravity wave is Doppler-shifted to zero and its energy may be absorbed into the background flow.

Figure 3 shows the results of a 1-year investigation of $\mathrm{OH}$ wave data imaged using the USU all-sky imager sited at Cachoeira Paulista, Brazil $\left(23^{\circ} \mathrm{S}\right)$ (Medeiros et al., 2003). This figure compares measurements of the wave velocities observed during the summer and winter seasons (four months each). Note, only sparse data were obtained during the equinox periods and are not shown here. Each plot shows the horizontal direction of motion of quasi-monochromatic waves versus their observed wave speed. It is clear that during the course of the year the dominant direction of the waves switches over from eastward in the summer months to mainly westward in the winter months. This result is consistent with the reversal of the stratospheric winds, whose magnitudes are comparable to the wave phase speeds, and suggests that, at least at low-latitudes, the small-scale gravity wave flux is being modulated strongly by the middle atmospheric wind field. This situation is indicated by the shaded areas that represent height-integrated "blocking regions". These are forbidden regions for the waves resulting from wind filtering at lower altitudes and were constructed using CIRA-86 climatological wind profiles. The prevailing direction of the wave ensemble is clearly opposite to that of the height integrated blocking region.

For comparison, Figure 4 shows the results of a similar wave analysis performed on two seasonal data sets obtained at Ft. Collins, Colorado $\left(40^{\circ} \mathrm{N}\right)$ and at BLO, Utah $\left(41.6^{\circ}\right)$. These sites are at similar latitudes but separated in longitude by $\sim 550 \mathrm{~km}$. In each of these figures the data have been summed into $15^{\circ}$ wide sectors and plotted versus number of events. The Ft. Collins data were obtained in 1997-1998 and show a marked meridional anisotropy with strong motions towards the north during summer and a switch over to a bimodal-like distribution during the win- 
ter months exhibiting strong southward motion, but also significant north-westward motion. These data also show a more subtle, but never the less a distinct zonal switch over from an eastward component of wave propagation during the summer months to a distinct westward component of wave propagation during winter, which is consistent with critical-layer blocking effects. However, the dominance of the meridional signature is unexpected. The BLO data were recorded during 2002 and 2003 and show remarkable similarities to the Ft. Collins data for both the summer and winter seasons with dominant northward (poleward) motion during the summer and bimodal propagation during the winter months. (Note the change of scale in Figure $4 \mathrm{~d}$ due to reduced number of events observed during the wintertime at BLO.) As these two data sets were taken from similarly located sites but separated in time by $\sim 5$ years they clearly show that this reversal is a recurrent seasonal effect (at least at mid-latitudes).
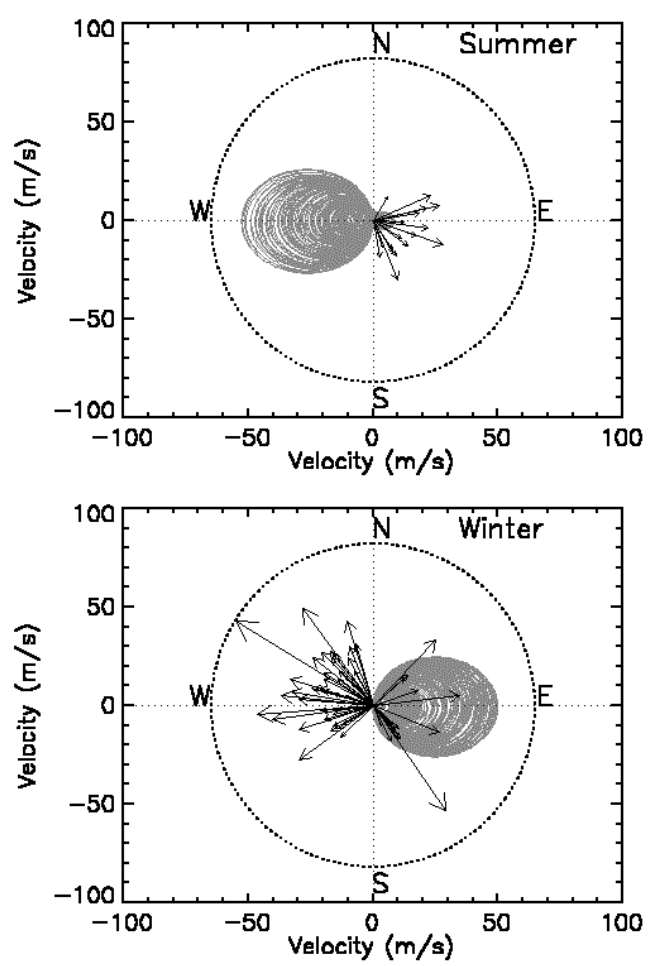

Figure 3 - Effect of seasonal variability on the propagation of short-period gravity waves observed from Cachoeira Paulista, Brazil $\left(23^{\circ} \mathrm{S}, 45^{\circ} \mathrm{W}\right)$. The solid arrows show the magnitudes and directions of the horizontal phase speed of the waves imaged in the $\mathrm{OH}$ emission for summer and winter seasons. The shaded areas represent the expected blocked directions for wave propagation during these two seasons (due to background wind-filtering effects). Adapted from Medeiros et al. (2003).

Other observers have also reported anisotropy in their wave measurements (e.g. Nakamura et al., 1999; Walterscheid et al., 1999; Hecht et al., 2001), some with strong meridional aniso- tropy. Walterscheid et al. (1999) suggested this could be due to wave ducting rather than wind filtering effects. Ducting can occur due to shears in the background winds in the MLT region (termed Doppler ducting) or to changes in the local temperature gradient (termed thermal or Brunt ducting). Due to their relatively small scale sizes, short-period waves are susceptible to both thermal and Doppler ducting in the vicinity of the mesopause (e.g. Chimonas \& Hines, 1986). Unlike freely propagating waves, ducted waves can travel large horizontal distances from their source regions and their impact on the MLT remains uncertain at this time. For example, an analysis of image data obtained from Hawaii during spring 1993 indicates that as much as $75 \%$ of the waves imaged over the mid-Pacific ocean exhibited ducted or evanescent characteristics (Isler et al., 1997). However, a recent study by Nielsen et al. (2006) suggests mainly freely propagating waves at high-latitudes during the winter months. Clearly further seasonal investigations of the nature (i.e. freely propagating or ducted) of short-period wave and their directional anisotropy are important.

\section{GRAVITY WAVE AND TIDAL TEMPERATURE PERTURBATIONS}

A new type of imager termed a "Mesospheric Temperature Mapper" (MTM) was developed at USU in the late 1990s. Like the all-sky camera systems this imager utilizes a high quantum efficiency ( $\sim 50 \%$ at NIR wavelengths) bare CCD array. The large dynamic range and low noise characteristics (dark current $\sim 0.1$ electrons $/ \mathrm{pixel} / \mathrm{sec}$ at $-50^{\circ} \mathrm{C}$ ) of this array together with its high linearity and stability provide an exceptional capability for longterm, quantitative measurements of the nightglow emissions. The camera has a $90^{\circ}$ field of view and is fitted with a fast $(\mathrm{f} / 5.6)$ telecentric lens system permitting narrow-band $(\sim 1.2 \mathrm{~nm})$ measurements of the $\mathrm{OH}$ Meinel $(6,2) \mathrm{P}_{1}(2)$ and $\mathrm{P}_{1}(4)$ rotational lines and two selected regions of the $\mathrm{O}_{2}(0,1)$ Atmospheric band to investigate the mesospheric temperature and intensity perturbations at two distinct altitudes ( $\sim 87$ and $\sim 94 \mathrm{~km}$, respectively). Spatial resolution in the zenith is about $0.9 \mathrm{~km}$ which is quite sufficient to resolve even the shortest scale gravity waves $\left(\lambda_{h}>5 \mathrm{~km}\right)$. In operation, sequential 60 -sec exposures are made: two $\mathrm{OH}$, two $\mathrm{O}_{2}$ and a background sky measurement at $857 \mathrm{~nm}$ resulting in an effective sampling rate of $\sim 6 \mathrm{~min}$. Rotational temperatures are computed using the ratio method, described by Meriwether (1975). Comparisons of the MTM temperatures with those obtained by other well calibrated instruments (Na temperature lidars and Fourier Transform Infra-red spectrometers) indicate that our absolute temperatures are reliable to $\pm 5 \mathrm{~K}$. However, the precision 


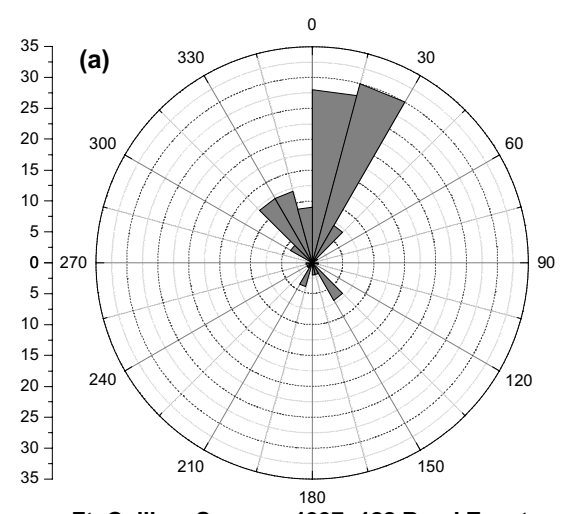

Ft. Collins, Summer 1997: 122 Band Events

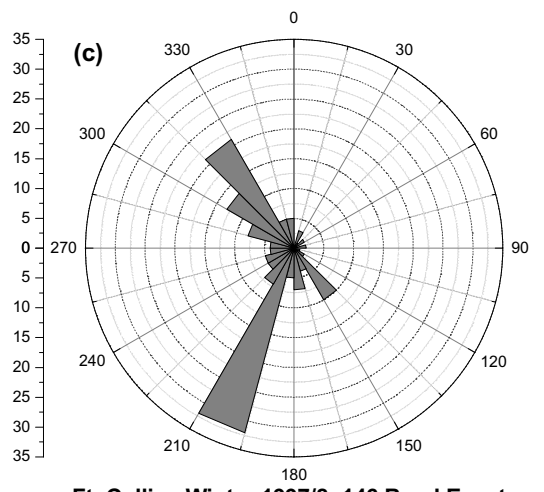

Ft. Collins Winter 1997/8: 146 Band Events

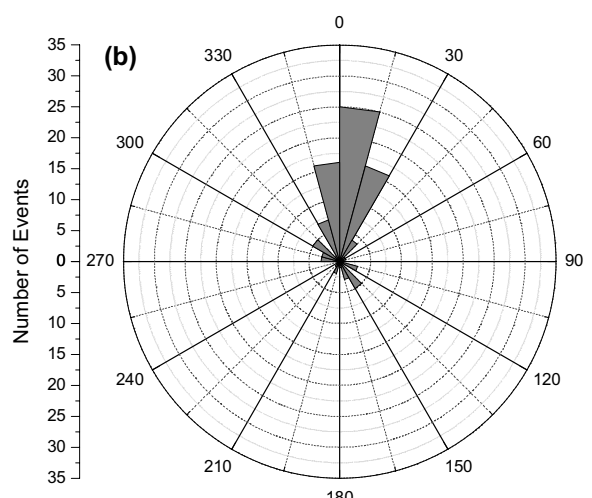

BLO Summer 2002: 97 Band Events

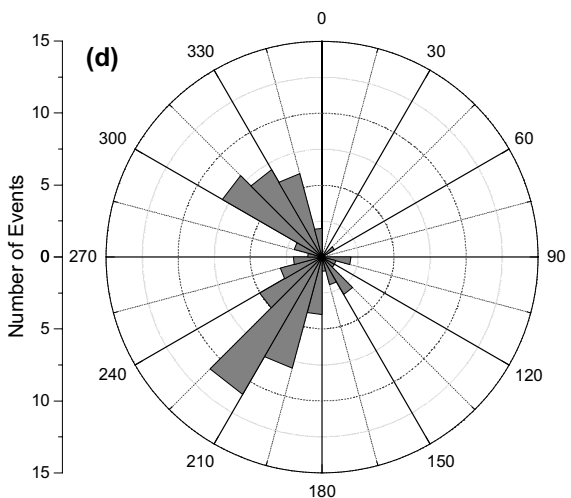

BLO Winter 2002/3: 70 Band Events

Figure 4 - Seasonal summer-winter comparison of short-period gravity wave anisotropy observed at Ft. Collins (1998) and BLO (2002-2003), two well separated but similar latitude sites in the USA. Both data sets are remarkably similar and exhibit strong meridional anisotropy, with a marked preference for northward wave motion during the summer months switching over to a bimodal-like distribution with strong southward wave motion. (Note the change of scale in Figure 4d.)

of the $\mathrm{OH}$ and $\mathrm{O}_{2}$ measurements (most important for determining wave perturbation amplitudes) is much higher at $\sim 1-2 \mathrm{~K}$ (Zhao et al., 2005).

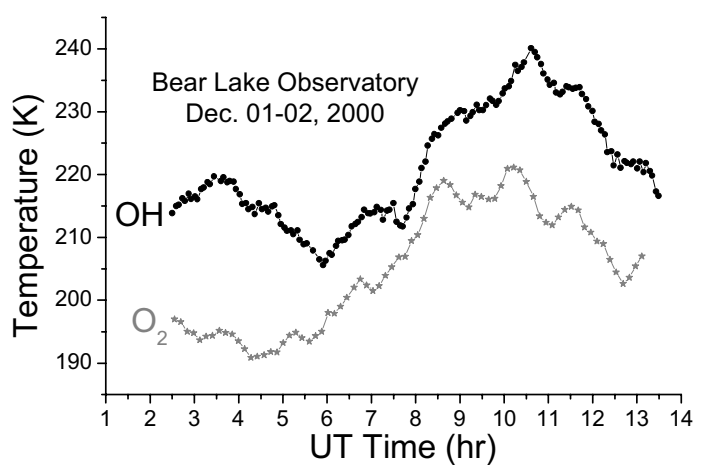

Figure 5 - Example MTM measurements of $\mathrm{OH}$ and $\mathrm{O}_{2}$ temperature showing a large amplitude tidal oscillation of period $\sim 11$ hours with superposed smallerscale gravity wave of $\sim 80$ min period. The data were obtained from BLO on 1/2 December 2000 and show a marked phase shift with $\mathrm{O}_{2}$ leading signal indicative of a downward progressing tide.
The MTM has been used on several extended campaigns to investigate gravity wave and tidal harmonic characteristics and most recently to study the characteristics of the semi-annual oscillation (SA0) at low-latitudes. Figure 5 shows an example of a long period $(\sim 11 \mathrm{hr})$ oscillation and a superimposed shorter period wave ( $~ 80 \mathrm{~min}$ ) evident in both the $\mathrm{OH}$ and $\mathrm{O}_{2}$ emissions. The data were obtained from BLO on 2 December 2000. A marked phase shift ( $\sim 1$ hour) exists between the two large amplitude waves with the 02 signal clearly leading the $\mathrm{OH}$ oscillation indicative of a downward progressing semidiurnal tide. The same signatures are evident in the respective band intensity data (not shown) which also yield information on the relative phase relationships between the intensity and temperature waves and their amplitudes. The ability to measure the temperature perturbations $(\Delta T / T)$ as well as the intensity variations $(\Delta \mathrm{l} / \mathrm{l})$ induced by the passage of monochromatic gravity waves provides a new method for estimating their momentum flux, when combined with information on 

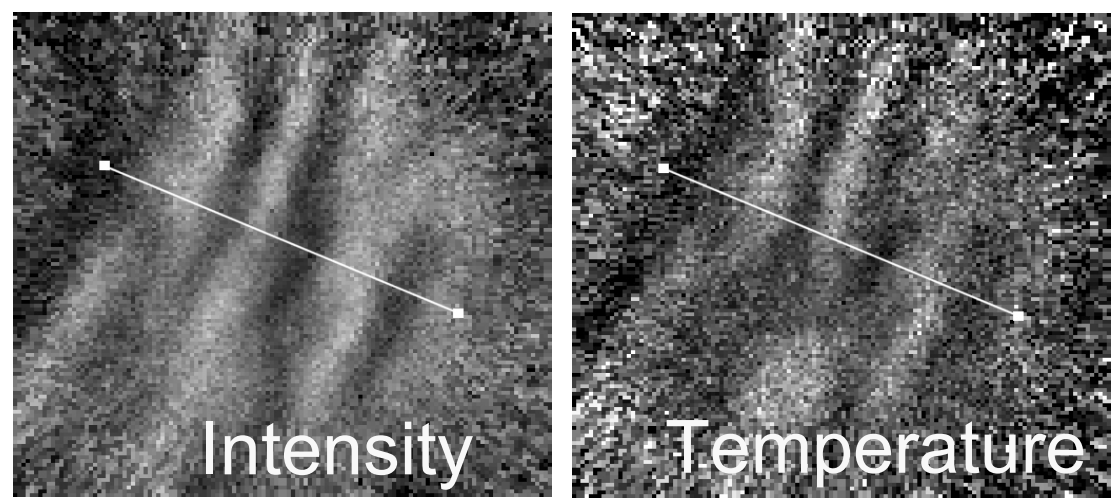

Figure 6 - Maps of $\mathrm{OH}(6,2)$ band intensity and rotational temperature derived from MTM data obtained on 11 April, 2002. The observed period of the gravity wave was $17 \mathrm{~min}$. The lines marks location of intensity and temperature scans shown in Figure 7.

their intrinsic wave parameters (e.g. Swenson et al., 1999; Taylor et al., 2001).

This technique is illustrated in Figure 6 which shows maps of intensity and $\mathrm{OH}$ rotational temperature derived from the MTM. The data were obtained from the summit of Haleakela Crater, Maui, Hawaii as part of the Maui-MALT program. The figures show a short observed period gravity wave imaged on 11 April, $2002\left(\lambda_{h}\right.$ $=37 \mathrm{~km}, \mathrm{v}_{\mathrm{h}}=36 \mathrm{~m} / \mathrm{s}$, observed period of $\left.17 \mathrm{~min}\right)$. The black lines in each case show the location of intensity and temperature scans used to determine the amplitude and phase of the wave in each case (see Fig. 7). Simultaneous wind measurements (not shown) have been used to determine the intrinsic wave period and to show that this wave was freely propagating (using the "vertical wave number squared" method described by Isler et al., 1997). Using these data an estimate of the horizontal momentum flux of this quasi-monochromatic wave can be obtained using the method described in Liu \& Swenson (2003). Using an estimated BruntVaisala period of 5 min (derived from simultaneous Na lidar temperature data), the magnitude of the momentum flux was found to be $30 \pm 10 \mathrm{~m}^{2} / \mathrm{s}^{2}$. This is consistent with previous (limited) measurements using lidar and optical/image methods (e.g. Gardner et al., 1999; Swenson et al., 1999) for a relatively low-contrast wave event but well below that determined by Fritts et al. (2002) for a high-contrast wave breaking event reported by Yamada et al., 2001. This example illustrates the capability of the MTM when combined with simultaneous Na lidar data for accurate momentum flux measurements.

For the past four years the MTM has operated near-continuously from the U.S. Air Force Maui Optical Station (AMOS) on Haleakala Crater, Maui, Hawaii. Our primary goal has been to obtain long-term coordinated measurements using a cluster of instruments including and Na wind-temperature lidar, a meteor wind radar and other passive optical measurements. These data were obtained as part of a joint NSF/AFOSR (Air Force Office of Scientific Research) sponsored Maui-MALT initiative. Figure 8 illustrates this new capability of the MTM for long-term, seasonal and inter-annual variability studies (Taylor et al., 2005). The figure shows three consecutive years of data from 2002 to 2004 inclusive. The "error bars" represent the standard deviation on the nocturnal temperature variability for each night due mainly to geophysical variability (tides).

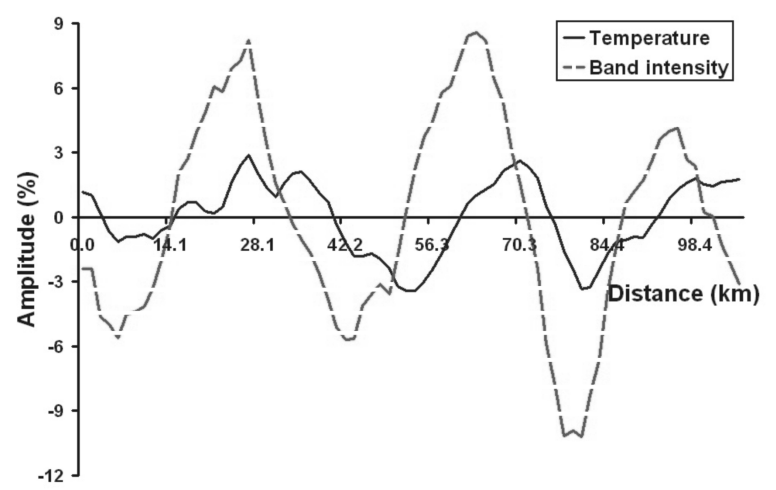

Figure 7 - Plot of relative band intensity and rotational temperature perturbation amplitudes for the data of Figure 6.

Previous airglow measurements at equatorial and lowlatitudes from Brazil have shown the presence of a strong SAO in emission intensity and temperature (Takahashi et al., 1995). Our data recorded at low-latitudes $\left(\sim 20^{\circ} \mathrm{N}\right)$ show evidence of an $\mathrm{SAO}$ and possibly an annual oscillation $(\mathrm{AO})$ in $\mathrm{OH}$ temperature (and $\mathrm{O}_{2}$ temperature, not shown here). This is illustrated by the solid curve in Figure 8 which shows a least-squares-fit assuming 


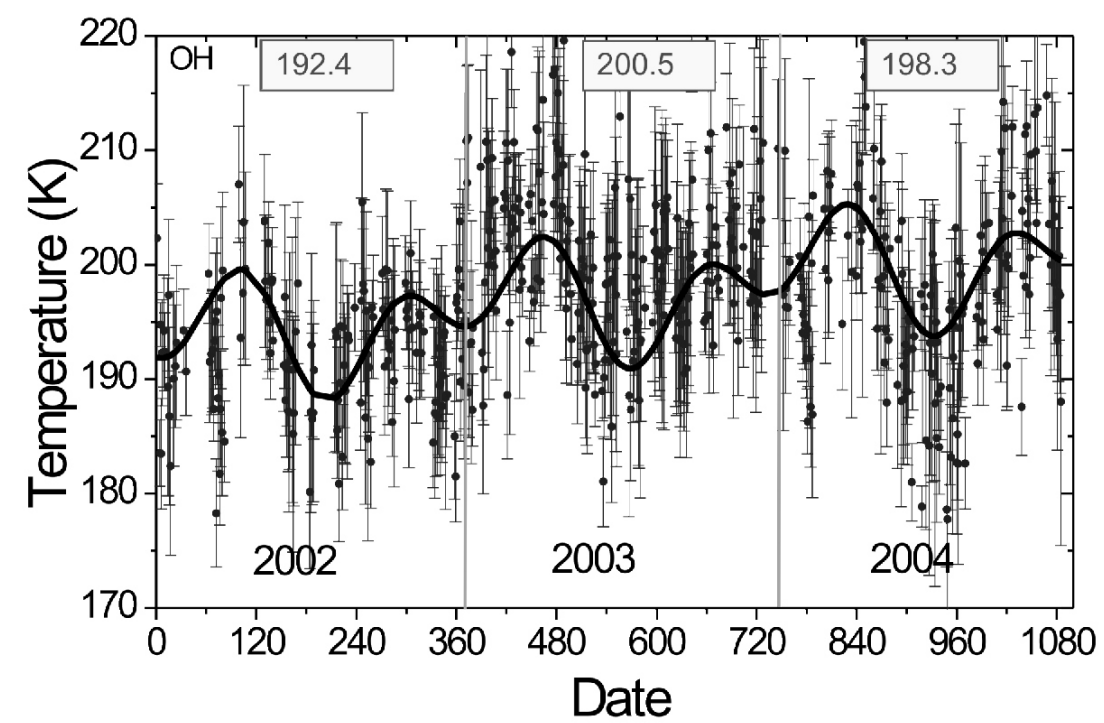

Figure 8 - Plot of nightly averaged OH rotational temperatures for three consecutive years 2002-2004. (Note, only data $>4$ hours in duration are shown). The data show evidence of a semi-annual oscillation as well as an annual oscillation as expected from this low-latitude site but rarely measured to date.

a mean, $\mathrm{AO}$ and an SAO oscillation. The amplitude of each component is similar at $\sim 3.5 \mathrm{~K}$. This study is still in progress but has already yielded a significant amplitude $\mathrm{SAO}$ in $\mathrm{OH}$ and $\mathrm{O}_{2}$ temperatures consistent with the southern hemisphere observations by Takahashi et al. (1995). The marked asymmetry in the spring and autumnal amplitudes was not evident in the equatorial data of Takahashi et al. (1995) but is most suggestive of a significant annual component. The high "density" of the data points illustrates well the capability of the MTM for long-term measurements.

\section{SUMMARY}

Image measurements of the nightglow emissions, which were once considered a novelty, have now proven to be an essential element in the quantitative investigation of gravity wave forcing of the MLT region. In particular their sensitivity to small-scale waves as well as their adaptability to multi-wavelength radiance and temperature measurements makes them a powerful tool for dynamical studies. The two-dimensional image data provide a direct measure of wave anisotropy, important for investigating wind filtering and ducting effects as well as novel data on wave breaking and turbulence leading to the transfer of momentum into the background flow. Ongoing observations as part of the Maui-MALT initiative are providing important new data on seasonal variability of mesospheric temperature as well as short-period gravity waves over the central Pacific Ocean where deep convective forcing is expected to be the dominant source mechanism for wave generation.

\section{ACKNOWLEDGEMENTS}

We wish to thank University of Illinois lidar group for the use of their wind/temperature data for our preliminary short-period momentum flux wave studies. We gratefully acknowledge the US NSF and AFOSR for their continued support of the Maui-MALT measurements at the AMOS Facility, Maui, HI. Funding for this research has been provided in part by the following grants for the NSF ATM 0003218, ATM 0000959 and ATM0455259 and NASA grant NNG04GA13G.

\section{REFERENCES}

CHIMONAS G \& HINES C0. 1986. Doppler ducting of atmospheric gravity waves. J. Geophys. Res., 91: 1219.

FRITTS DC \& VINCENT RA. 1987. Mesospheric momentum flux studies at Adelaide, Australia: Observations and gravity wave-tidal interaction mode. J. Atmos. Sci., 44: 605

FRITTS DC, VADA SL \& YAMADA Y. 2002. An estimate of strong local body forcing and gravity wave radiation based on $\mathrm{OH}$ airglow and meteor radar observations. Geophys. Res. Lett., 29: 71.

GARCIA RR \& SOLOMON S. 1985. The effect of breaking gravity waves on the dynamics and chemical composition of the mesosphere and lower thermosphere. J. Geophys. Res., 90: 3850.

GARDNER CS, GULATI K, ZHAO Y \& SWENSON G. 1999. Measuring gravity wave momentum fluxes with airglow imagers. J. Geophys. Res., 104: 11,903-11,915. 
HECHT JH. 2004. Instability layers and airglow imaging. Rev. Geophys., 42: RG1001, doi:10.1029/2003RG000131.

HECHT JH, WALTERSCHEID RL, HICKEY MP \& FRANKE SJ. 2001. Climatology and modeling of quasi-monochromatic atmospheric gravity waves observed over Urbana, Illinois. J. Geophys. Res., 106: 5181-5195.

HOLTON JR. 1983. The influence of gravity wave breaking on the circulation of the middle atmosphere. J. Atmos. Sci., 40: 2497-2507.

ISLER JR, TAYLOR MJ \& FRITTS DC. 1997. Observational evidence of wave ducting in the mesosphere. J. Geophys. Res., 102: 26301.

LIU AZ \& SWENSON GR. 2003. A modeling study of 02 and OH airglow perturbations induced by atmospheric gravity waves. J. Geophys. Res., 108: 4151.

MEDEIROS AF, TAYLOR MJ, TAKAHASHI H, BATISTA PP \& GOBBI D. 2003. An investigation of gravity wave activity in the low-latitude upper mesosphere: Propagation direction and wind filtering. J. Geophys. Res., 108: 4411.

MEDEIROS AF, BURITI RA, MACHADO EA, TAKAHASHI H, BATISTA PP, GOBBI D \& TAYLOR MJ. 2004. Comparison of gravity wave activity observed by airglow imaging from two different latitudes in Brazil, J. Atmos. Solar-Terr. Phys, 60: 647-654, doi: 10.1016/j.jastp.2004.01.016.

MERIWETHER JW. 1975. High latitude airglow observations of correlated short-term fluctuations in the hydroxyl Meinel 8- 3 band intensity and rotational temperature, Planet. Space Sci., 43: 1211-1221.

NAKAMURA T, HIGASHIKAWA A, TSUDA T \& MATSUSHITA Y. 1999. Seasonal variations of gravity wave structures in $\mathrm{OH}$ airglow with a CCD imager at Shigaraki. Earth Planets Space, 51: 897-906.

NIELSEN K, TAYLOR MJ, PAUTET PD, FRITTS DC, MITCHELL N, BELDON C, SINGER W, SCHMIDLIN FJ \& GOLDBERG RA. 2006. Propagation of short-period gravity waves at high-latitudes during the MaCWAVE winter campaign. Ann. Geophys., 24: 1-17.

STATES RJ \& GARDNER CS. 2000. Thermal structure of the mesopause region (80-105 km) at $40^{\circ} \mathrm{N}$ latitude. Part Il: diurnal variations. J. Atmos. Sci., 57: 78-92.

SWENSON GR, HAQUE R, YANG W \& GARDNER CS. 1999. Momentum and energy fluxes of monochromatic gravity waves observed by an $\mathrm{OH}$ imager at Starfire Optical Range, NM. J. Geophys. Res., 104: 6067.
TAKAHASHI H, CLEMESHA BR \& BATISTA PP, 1995. Predominant semiannual oscillation of the upper mesospheric airglow intensities and temperatures in the equatorial region. J. Atmos. Terr. Phys., 57(4): 407-414.

TAYLOR MJ \& HAPGO0D MA. 1990. On the origin of ripple-type wave structure in the $\mathrm{OH}$ nightglow emission. Planet Space Sci., 38: 14211430.

TAYLOR MJ, RYAN EH, TUAN TF \& EDWARDS R. 1993. Evidence of preferential directions for gravity wave propagation due to wind filtering in the middle atmosphere. J. Geophys. Res., 98 (A4): 6047.

TAYLOR MJ, BISHOP MB \& TAYLOR V. 1995. All-sky measurements of short period waves imaged in the $0 \mathrm{I}(557.7 \mathrm{~nm}), \mathrm{Na}(589.2 \mathrm{~nm})$ and near infrared $\mathrm{OH}$ and $\mathrm{O}_{2}(0,1)$ nightglow emissions during the $\mathrm{ALOHA}-93$ campaign. Geophys. Res. Lett., 22: 2833.

TAYLOR MJ, GARDNER LC \& PENDLETON JR. WR. 2001. Long-period wave signatures in mesospheric $\mathrm{OH}$ Meinel $(6,2)$ band intensity and rotational temperature at mid-latitudes. Adv. Space Res., 27: 1171-1179.

TAYLOR MJ, TAORI AK, HATCH DR, LIU HL \& ROBLE RG. 2005. Characterization of the semi-annual-oscillation in mesospheric temperatures at low-latitudes. Adv. Space Res., 35: 2037-2043.

TUAN TF \& TADIC D. 1982. A dispersion formula for analyzing 'modal interference' among guided and free gravity wave modes and other phenomena in a realistic atmosphere. J. Geophys. Res., 87: 1648.

WALTERSCHEID RL, HECHT JH, VINCENT RA, REID IM, WOITHE J \& HICKEY MP. 1999. Analysis and interpretation of airglow and radar observations of quasi-monochromatic gravity waves in the upper mesosphere and lower thermosphere over Adelaide, Australia $\left(35^{\circ} \mathrm{S}\right.$, $138^{\circ}$ E). J. Atmos. Solar-Terr. Phys., 61: 461-478.

YAMADA Y, FUKUNISHI H, NAKAMURA T \& TSUDA T. 2001. Breaking of small-scale gravity wave and transition to turbulence observed in $\mathrm{OH}$ airglow. Geophys. Res. Lett., 28(11): 2153-2156.

ZHAO Y, TAYLOR MJ \& CHU X. 2005. Comparison of simultaneous Na lidar and mesospheric nightglow temperature measurements and the effects of tides on the emission layer height. J. Geophy. Res., 110: D09S07, doi:10.1029/2004JD005115.

\section{NOTES ABOUT THE AUTHORS}

Michael J Taylor gained his Bachelors degree (with honors) in Physics in 1974. A Masters degree in Electronic in 1977 and a Ph.D in Atmospheric Physics in 1986 all from the University of Southampton, U.K. Currently he is a Professor of Physics in the Center for Atmospheric and Space Sciences and Physics Department at Utah State University, USA. His primary research interests are low-light imaging of a broad range of atmospheric phenomena focusing on mesospheric dynamics.

William R. Pendleton, Jr. is Professor emeritus at Utah State University. He gained a Bachelors of Arts degree at William Jewell College, Liberty, Missouri in 1959 and a Ph.D. in Physics at the University of Arkansa in 1964. He joined Utah State University in 1966 where he specialized in airglow and auroral energetics and spectroscopy. 
Pierre-Dominique Pautet gained his Bachelors degree in Applied Physics in 1995 and his Masters degree in Image Processing in 1996 from University of Bourgogne, France. He gained his Ph.D. in Image Processing in 2000 from the University of Franche-Comte, France. He worked as a Post Doctoral Fellow in Center for Atmospheric and Space Sciences at Utah State University from 2001-2006 specializing in airglow and sprite measurements.

Yucheng Zhao gained her Bachelors degree in Meteorology in 1988 and her Masters degree in Atmospheric dynamics in 1991, both from China. She obtained her Ph.D. in Atmospheric Sciences from University of Illinois in 2000. She is a Senior Research Associate working in the Center for Atmospheric and Space Sciences at Utah State University. Her research focuses on mesospheric dynamics.

Chris Olsen gained his Bachelors degree in Physics at Utah State University in 2004. As an undergraduate student he worked as a data analysis in the Center for Atmospheric and Space Sciences at Utah State University. He is currently serving as a U.S. Naval Officer.

Hema Karnam Surendra Babu gained her Bachelors of Technology degree in Electronics and Communications Engineering at the Jawaharlal Nuhru Technological University, Hyderabad, India in 2001. She gained her Masters degree in Electrical and Computer Engineering at Utah State University in 2006.

Amauri Fragoso de Medeiros is a Physics professor at Federal University of Campina Grande (UFCG), Brazil. He is graduated in Physics at the Regional University of the Northeast (URNe), Brazil, obtained his MSc. Degree in Science Teaching from São Paulo University (USP), Brazil, and his Ph.D. in Space Geophysics from the National Institute for Space Research (INPE). His present research interests include the dynamics of the upper mesosphere using airglow and meteor radar experiments and irregularities in the ionosphere.

Hisao Takahashi is a researcher at the National Institute for Space Research (INPE) since 1970. He received his BSc. and MSc. in Physics at the Niigata University $(1968,1970)$ and obtained his Ph.D. in Space Sciences at the INPE (1980). His research interests include behavior studies of the airglow, dynamics and chemistry of the upper mesosphere and ionosphere. 